\title{
ULTRAFILTRATION PROCESSES FOR REMOVING HUMIC SUBSTANCES: EFFECT OF MOLECULAR WEIGHT FRACTIONS AND PAC TREATMENT
}

\author{
CHENG-FANG LIN'*, YUH-JAY HUANG ${ }^{1}$ and OLIVER J. HAO ${ }^{2 \circledast}$ \\ ${ }^{1}$ Graduate Institute of Environmental Engineering, National Taiwan University, Taipei, Taiwan and \\ ${ }^{2}$ Department of Civil Engineering, University of Maryland, College Park, MD 20742, U.S.A.
}

(First received January 1998; accepted in revised form July 1998)

\begin{abstract}
The role of humic substances in general and different molecular weight fractions of humic substances in particular on the membrane performance in terms of quality (chlorination byproducts) and quantity (permeate flux) is unclear. One of the goals of the present study is to evaluate the effect of fractionated humic substances on the ultrafiltration (UF) performance. A commercial humic solution was subject to gel filtration chromatography, and the resultant four fractions representing the apparent molecular weight (AMW) from 180 to 22,600 Daltons (Da) were filtered through a single module UF system, with a molecular weight cutoff $100 \mathrm{kDa}$. The fraction with the largest AMW (6.5-22.6 kDa) exhibits the worst flux decline with the best permeate quality, whereas the smallest AMW fraction (160-650 Da) exerts little effect on flux decline. Although the UF system is able to remove a significant portion of THMFP (trihalomethanes formation potential) in larger AMW fractions, the permeate THM in terms of $\mu \mathrm{g}$ THMs $/ \mathrm{mg}$ carbon is still high. Thus, UF systems are not effective in removing disinfection-byproducts. The use of powdered activated carbon (PAC) for pretreatment of humic substances, or in combination with different UF operating systems, to reduce membrane fouling actually yields adverse effects. The PAC was ineffective in removing those AMW fractions less than 300 or greater than $17,000 \mathrm{Da}$; the higher the PAC dosage, the more removal in the middle range of thee AMW factions. The flux decline for PAC-treated streams is worse than the original humic substances. Similarly, the combined UF-PAC system significantly decreases the flux. (C) 1999 Elsevier Science Ltd. All rights reserved
\end{abstract}

Key words - ultrafiltration, humic acids, apparent molecular weight, activated carbon, flux, membrane fouling

\section{INTRODUCTION}

The use of low pressure membrane process has received considerable attention lately in the water utility industry to meet the stringent drinking water standards, specifically for removing natural organic matter (NOM) in general and minimizing disinfection-by-products (DBPs) in particular. The recent 1996 Safe Drinking Water Act of the U.S.A. requires that the U.S. EPA promulgates Stage I Disinfectant-Disinfection By-products Rule by November 1998, and Stage II Rule by May 2002 (Pontius, 1997) for total trihalomethanes (TTHMs) and total haloacetic acids (THHAs). Currently, the maximum contaminant level (MCL) for TTHMs is $100 \mu \mathrm{g} / 1$, and Stage 1 Rule proposes the MCLs for four THMs (chloroform, bromodichlomethane, chlorobromomethane and bromoform) and five HAAs (monochloroacetic acid, monobromoacetic acid, dichloroacetic acid, trichloroacetic acid and dibromoacetic acid) at 80 and $60 \mu \mathrm{g} / \mathrm{l}$, respectively

*Author to whom correspondence should be addressed [Fax: + 886-2-23927653]
(Pontius, 1995). It is expected that Stage 2 Rule will further reduce the MCLs to 40 and $30 \mu \mathrm{g} / 1$, respectively, for TTHMs and THAAs.

Simplicity of operation, development of higher flux membranes with low fouling potentials and lower membrane costs have contributed to its world wide applications in small systems (Adham et al., 1996). In fact, membrane processes showed comparable or lower costs compared with conventional treatment for small systems of $<20,000 \mathrm{~m}^{3} / \mathrm{d}$, or $5 \mathrm{mg}$ d (Wiesner et al., 1994; Jacangelo et al., 1995). Unfortunately, membrane processes are still not widely recognized as a popular alternative to other processes, partly due to lack of understanding of some process fundamentals, including factors affecting permeate flux and membrane fouling, as well as permeate quality in terms of regrowth potential and DBP formation potential.

Recently, many studies have been performed on membrane system in general and ultrafiltration (UF) in particular. The latter includes modeling UF performance (Adham et al., 1993; Jones et al., 1993), assessing UF for particulate removal (Jacangelo et al., 1989) and for DBP control (Laine 
et al., 1993), cost analysis (Adham et al., 1996), effect of membrane type (Laine et al., 1989; Nakatsuka et al., 1996) and membrane integrity (Adham et al., 1995), combined powdered activated carbon (PAC)-UF system for organic removal (Adham et al., 1991, 1993) and DBP control (Jacangelo et al., 1995), iron oxide-UF system for NOM removal (Chang and Benjamin, 1996), as a pretreatment unit for subsequent nanofiltration (NF) process (Chellam et al., 1997), mass transport mechanisms (Lee and Clark, 1997) and UF for europium removal (Norton et al., 1997). Typically, UF employs a low pressure system $(40-1000 \mathrm{kPa})$, has a relatively large pore size $(0.001-0.1 \mu \mathrm{m})$ and a higher MWCO (molecular weight cutoff) of $100 \mathrm{kDa}$; hence, UF yields higher permeate flux and saves significant operating costs, as compared to reverse osmosis systems (Laine et al., 1989). General consensuses about the UF system are that it is effective in reducing turbidity, particulates, suspended solids and total coliforms as well as HPC (hetrotrophic plate count) bacteria (Jacangelo et al., 1989).

Typically, the capability of UF in removing NOM depends on the type as well as the MWCO of the membrane used, physical and chemical nature of NOM, interaction between NOM and membrane surface and UF operating conditions. Because of relatively higher MWCO, the UF system may not be effective for removal of DBP precursors (Laine et al., 1989; Jacangelo et al., 1995). For example, Laine et al. (1993) evaluated the capability of UF (MWCO $100 \mathrm{kD}$ ) for removal of DBP precursors with two California surface waters and the third one from Ottawa, Ont. Their results indicated that UF was ineffective for controlling the formation of DBPs, whereas NF with an MWCO of 400-800 Da effectively controlled DBP formation (Fu et al., 1994; Agbekodo et al., 1996).

There is limited information on the effect of molecular weight (MW) of humic substances on UF performance, although some MW studies of humic substances have been conducted on NF permeate flux (e.g., Nilson and DiGiano, 1996). Thus, the extent of the different MW constituents of humic substances on UF permeate decline is unclear. One would imagine that the larger $\mathrm{MW}$ fractions of humic substances would significantly affect permeate decline. What is the role of smaller MW fractions in membrane fouling? These molecules are supposedly passing through the membrane and should play a minor role in membrane fouling.

To enhance organic removal and to reduce membrane fouling causing by potential hydrophobic substances, the use of PAC for raw water pretreatment or in combination with the UF system has been practiced. Some studies have indicated that the addition of PAC could increase membrane flux (Pirbazari et al., 1992; Jacangelo et al., 1995; Kim et al., 1996) and enhance organic removal (Adham et al., 1991, 1993). However, other studies have indicated that the coagulated effluent (LahoussineTurcaud et al., 1990) or humic residuals after PAC treatment (Nilson and DiGiano, 1996) in fact facilitates permeate decline. What is the range of the MW of the PAC-treated water affecting UF permeate flux? Is the integrated UF-PAC system really enhancing UF performance? Which MW fraction of humic substance is responsible for THM formation? The present study will attempt to address these issues.

Specifically, the goals of this study were to evaluate the following factors affecting the UF performance: (1) MW of humic substances, (2) PAC as a pretreatment and (3) combined UF-PAC system. The humic substances were fractionated based on their MW classification. As a result, UF permeate flux decline and the corresponding membrane fouling causing by the specific MW class of humic substance in the absence/presence of PAC can be better understood. Thus, the role of PAC in UF application in terms of permeate quality and flux can be defined.

\section{MATERIALS AND METHODS}

\section{Feed water}

The commercial humic acid (Aldrich) and its MW fractions were used as the feed water. A stock solution was prepared by dissolving $500 \mathrm{mg}$ humic acid in 1-1 deionized water (Milli-Q) and filtering through $0.45 \mu \mathrm{m}$ membrane filter. The filtrate was stored at $4^{\circ} \mathrm{C}$ for subsequent uses.

\section{Fractionation of humic acid}

The stock humic solution was subject to gel filtration chromatography (GFC) for fractionating humic substances with respect to its apparent molecular weight (AMW). The Sephadex G-75 gel (Pharmacia) was employed as a packing material. Blue dextran (Pharmacia) was used to calculate the bulk void volume of the column (C 16/70, Pharmacia). The chemical PEG, polyethylen glycol (Merck), with its respective MW of $400,1500,6000$, 10,000 and 20,000 , was used to calibrate the column AMW. The eluent was collected in a fraction collector and four fractions were thus obtained for subsequent UF and PAC experiments. Each fraction was analyzed for dissolved organic carbon (DOC), UV absorbance and THM formation potential (THMFP).

\section{$P A C$}

PAC obtained from Sigma (C-5260) was used for pretreatment and combined PAC-UF studies. The BET surface area is approximately $730 \mathrm{~m}^{2} / \mathrm{g}$ with the average pore diameter $0.025 \mu \mathrm{m}$. The size ranges from 10 to $150 \mu \mathrm{m}$ with $D_{50}=50 \mu \mathrm{m}$; the iodine number is about $800 \mathrm{mg} / \mathrm{g}$ and ash content $6 \%$.

\section{UF membrane}

To observe flux decline within a reasonable time, a single hollow fiber membrane (hydrophobic with negatively charged polysulfone) with a relatively small area was used. The nominal MWCO is $100 \mathrm{kDa}$ and other characteristics of the membrane used is shown in Table 1. 
Table 1. Characteristics of UF membrane

\begin{tabular}{lc}
\hline Parameter & Characteristics \\
\hline Manufacturer & A/G technology \\
Configuration & hollow fiber \\
Type & Hydrophobic \\
Material & negatively charged polysulfone \\
Fiber diameter & $30 \mathrm{~mm}$ \\
Fiber length & $9.4 \mathrm{~cm}^{2}$ \\
Membrane area & single fiber \\
Module & $100 \mathrm{kDa}$ \\
MWCO & \\
\hline
\end{tabular}

\section{UF operation}

The UF system was operated at three different crossflow modes: (1) constant feed concentration, (2) circulating and (3) combined UF-PAC. At a constant pressure and velocity, both permeate and concentrate stream were recycled to the feed line to maintain a relatively constant DOC concentration under mode (1) conditions. For the circulating system (mode 2), only the concentrate stream was recycled to the raw water feed line to simulate the actual UF plant configuration. For the combined UF-PAC system (mode 3), the feed water was mixed with PAC for $2.5 \mathrm{~h}$ and the mixture was then pumped to the system operated in a circulating mode.

Additionally, diluted humic acid solution $(20 \mathrm{mg} / \mathrm{l})$ was pretreated with different amounts of PAC (up to $400 \mathrm{mg}$ / 1), and the resultant filtrate was subject to the UF system to observe any flux effect exhibited by the modified feed compositions. Each of the PAC pretreated stream was also fractionated with respect to its AMW for indication of any particular AMW effect on the membrane flux. Throughout the experiments, the transmembrane pressure was maintained at $138 \mathrm{kPa}$ and permeate flux was monitored. The permeate of some experiments was analyzed for its DOC and THM yield. The flow diagram of the overall experiment is illustrated in Fig. 1.

\section{Analysis}

DOC were analyzed on filtered samples $(0.45 \mu \mathrm{m})$ in an organic carbon analyzer (OI model 707). UV absorbance was measured with a UV/Vis spectrophotometer (Jasco, model 7850) at a single wavelength $254 \mathrm{~nm}$ with a $1-\mathrm{cm}$ path length. The procedures for the THMFP test followed the section $5710 \mathrm{~B}$ of the Standard Methods (APHA,

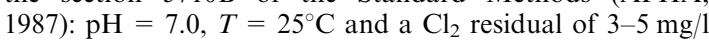
after $7 \mathrm{~d}$. For the determination of four THMs, the sample was initially subject to pentane extraction for $10 \mathrm{~min}$ and the upper layer was then injected into a Hewlett Packard GC (model 5890) unit with a fused silica capillary column and an electron capture detector.

\section{RESULTS AND DISCUSSION}

The normalized permeate fluxes under several experimental conditions as a function of time are shown in Fig. 2. The flux under five experiments in Fig. 2 is similar, i.e., $320 \pm 151 / \mathrm{m}^{2}$-h at $138 \mathrm{kPa}$, or $188 \pm 9 \mathrm{l} / \mathrm{m}^{2}$-h-bar. The results are all expected in that the flux declines rapidly in the presence of humic substances, that the decline is more noticeable in the circulating mode and that the feed with a higher DOC exerts the worst flux decline. The system reaches $60 \%$ of the initial capacity after only $3.5 \mathrm{~h}$ operation in the circulating system (Fig. 2(b)). The DOC in the loop at the end of experiment (330 $\mathrm{min}$ ) had increased to 280 and $137 \mathrm{mg} / 1$ for the original condition of $\mathrm{DOC}=5$ and $1.5 \mathrm{mg} / \mathrm{l}$, respectively.

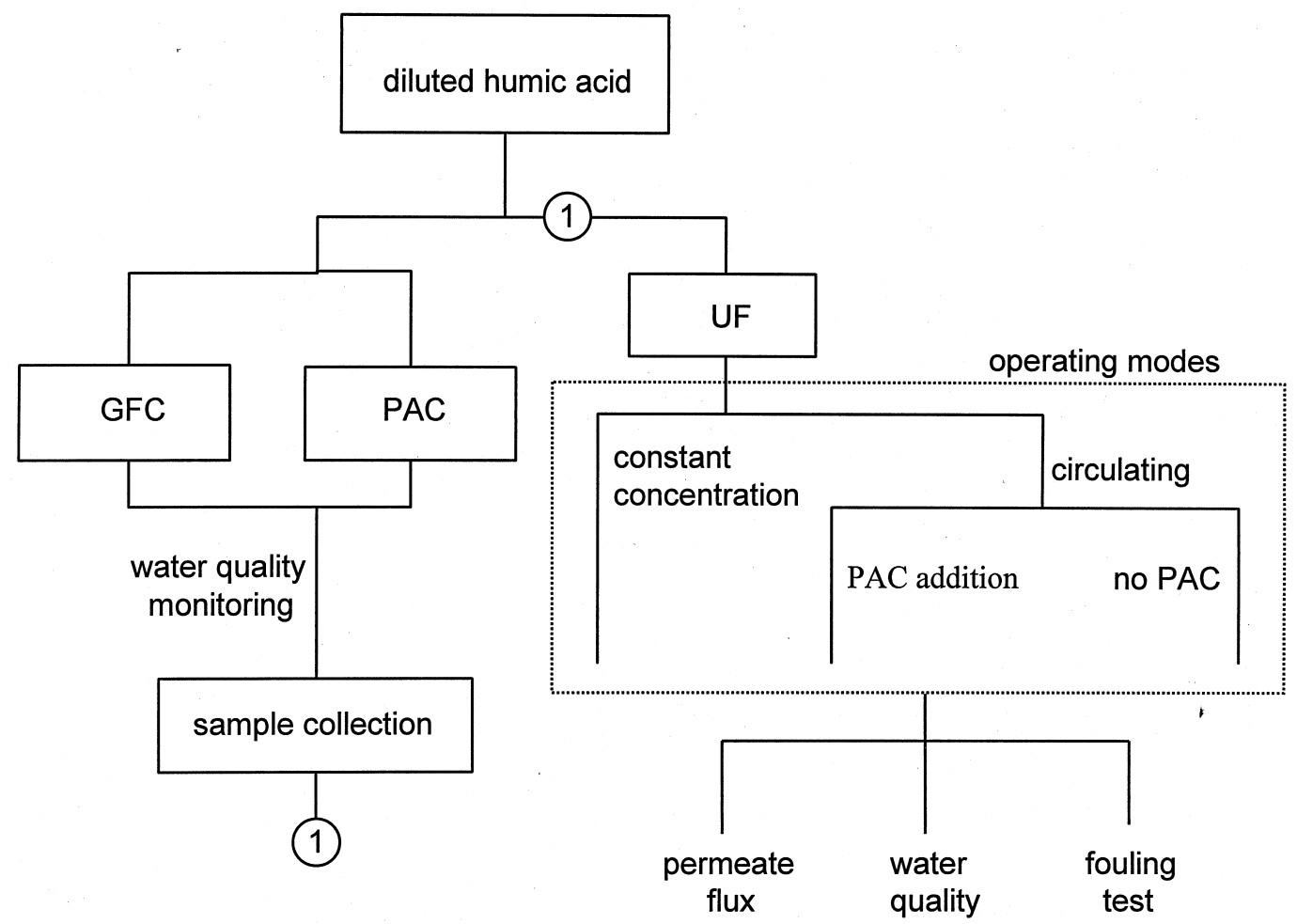

Fig. 1. A schematic diagram of the overall experimental approach. 


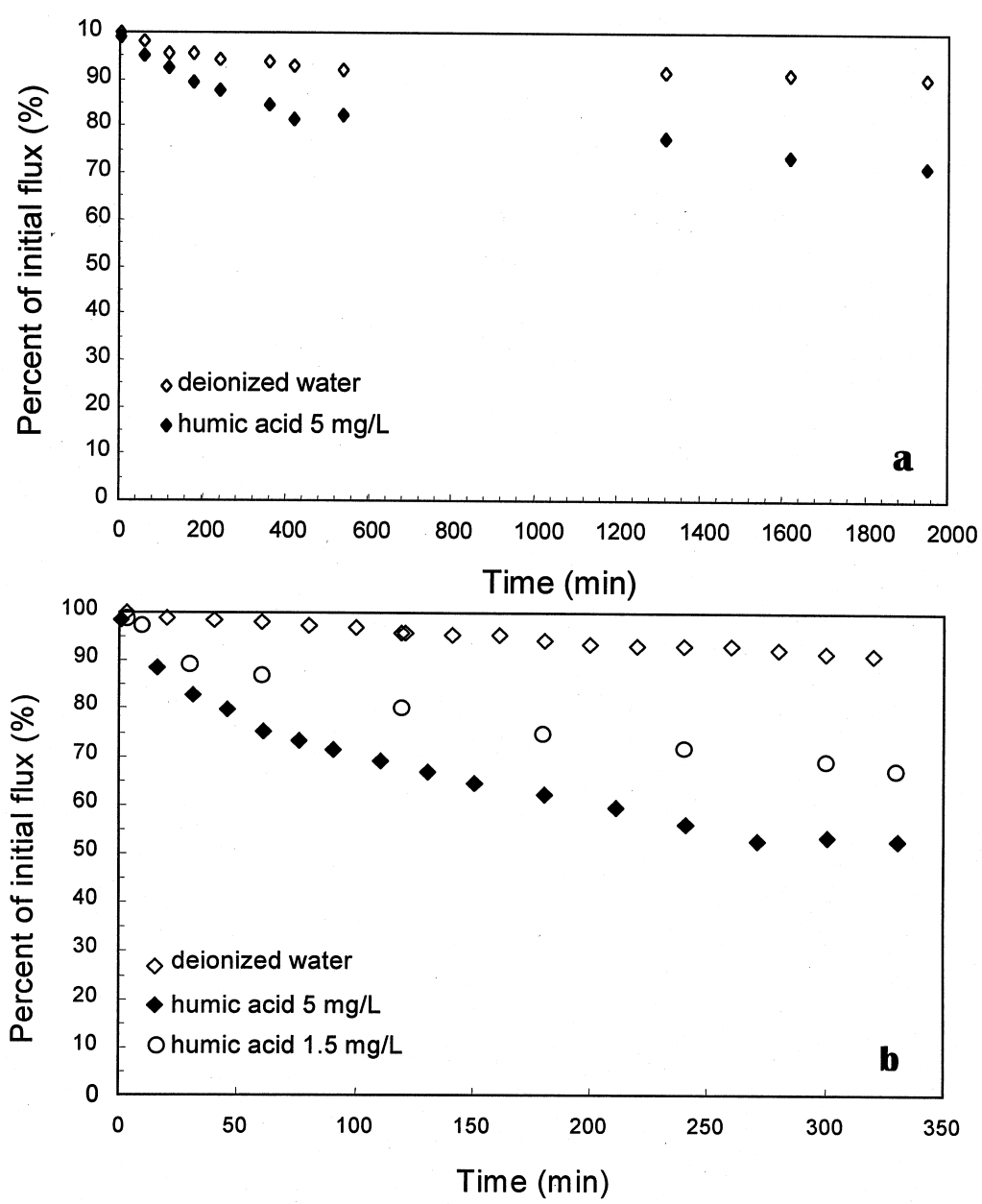

Fig. 2. Permeate flux of different UF systems: (a) constant feed concentration and (b) circulating mode.

\section{Effect of $A M W$ fractionation}

The MW calibration with PEG provides an excellent correlation between AMW (Da) and the elution parameter, $K_{\mathrm{av}}\left(R^{2}=0.98\right.$, not shown). The AMW of the diluted Aldrich humic acid with the corre- sponding UV and DOC data is shown in Fig. 3. Remarkably, the UV absorbance data correspond well with DOC in all AMW fractions. For comparison, the result of MW fractionation of the humic substances isolated from the Detroit River in

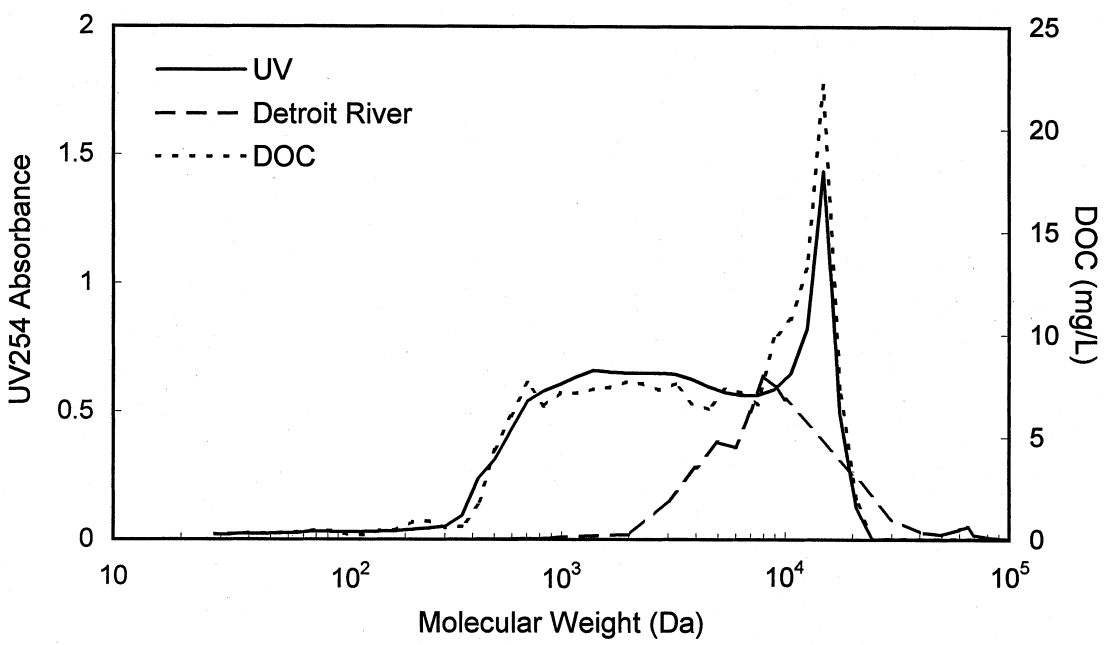

Fig. 3. GFC chromatograms for commercial humic substances. 
Table 2. Characteristics of fractionated humic substances

\begin{tabular}{|c|c|c|c|c|c|}
\hline Fractionated Group & AMW (Da) & $\operatorname{UV} 254\left(\mathrm{~cm}^{-1}\right)$ & DOC (mg/l) & UV/DOC $\left(\mathrm{m}^{2} / \mathrm{g}\right)$ & THM/DOC $(\mu \mathrm{g} / \mathrm{mg})$ \\
\hline G-1 & $6500-22,600$ & 0.684 & 10.9 & 6.3 & 181 \\
\hline $\mathrm{G}-2$ & $2200-6500$ & 0.595 & 7.0 & 8.5 & 179 \\
\hline G-3 & $650-2200$ & 0.652 & 7.5 & 8.7 & 165 \\
\hline G-4 & $180-650$ & 0.477 & 5.8 & 8.2 & 123 \\
\hline
\end{tabular}

Windsor, Ont. (Alarcon-Herrera et al., 1994) is included in Fig. 3. Although all these MW fractionations including the humic substances from Biscayne (FL) aquifer (Amy et al., 1987) use the same GFC technique (albeit with different compounds for MW calibration), the AMW distribution is different among the three humic substance sources. Particularly, the AMW fraction with the highest DOC occurs near $12 \mathrm{kDa}$ for the commercial humic substances, whereas, the values for the Detroit river and Biscayne groundwater correspond to 10 and $18 \mathrm{kDa}$, respectively.

Some chemical characteristics of four AMW fractions collected are shown in Table 2. The carbon mass recovered is about $92 \%$, indicating an acceptable analytical control. Contrast with other studies in which the majority of the THM precursors has an AMW fraction less than $1 \mathrm{kDa}$ (e.g., Kim and Symons, 1991; Amy et al., 1992), the results of the present study indicate that the fraction with the largest AMW (G-1) exhibits the highest THM yield (in $\mu \mathrm{g} \mathrm{THM} / \mathrm{mg}$ DOC).

The specific absorptivities or $\mathrm{UV} / \mathrm{DOC}$ ratios $\left(6.3-8.2 \mathrm{~m}^{2} / \mathrm{g}\right)$, are higher than those of different natural waters (1.5-6.4) as reported by others (Amy et al., 1992; Krasner et al., 1996). Hejzlar et al. (1994) have demonstrated that samples with higher absorptivities indicate high content of phenolic hydroxyls and low $\mathrm{H} / \mathrm{C}$ ratios, or high degree of aromaticity (Krasner et al., 1996) and other unsaturated configurations (Hozalski et al., 1995).
Thus, waters with high UV/DOC ratios exhibit a high reactivity to form THMs. It is not surprising that the values of THM yield of the present study are much higher than those from hydrophobic factions of different water sources, e.g., $55-114 \mu \mathrm{g} / \mathrm{mg}$ C (Collins et al., 1986), from natural waters and peat extracted fulvic acid (45-64 $\mu \mathrm{g} / \mathrm{mg} \mathrm{C}$, Amy et al., 1987), and from organic fraction with AMW $>0.5 \mathrm{kDa} \quad(60-80 \mu \mathrm{g} / \mathrm{mg} \quad \mathrm{C}, \quad \mathrm{Kim} \quad$ and Symons, 1991).

Each fraction was then diluted to the same DOC concentration $(5 \mathrm{mg} / \mathrm{l})$ and fed to the UF system operated under different modes as described before. The permeate flux with respect to AMW factions at the constant concentration mode (feed concentration variation after $20 \mathrm{~h}$ operation less than $0.2 \mathrm{mg} \mathrm{DOC} / \mathrm{l}$ ) is shown in Fig. 4. Clearly, the G-1 fraction (largest AMW) exerts the worst flux decline, and G-4 fraction (smallest AMW 180-650) the least. The smaller AMW fraction could easily be passed through membrane pore size resulting in a lesser membrane fouling. The middle AMW range (650-6500) of G-2 and G-3 fractions exhibits a similar trend. It is interesting to note that the flux decline for unfractionated humic acid (Fig. 2(a)) is in fact less than all these fractionated samples. The exact reason(s) is unclear, since the operating conditions and feed concentration (DOC $=5 \mathrm{mg} / \mathrm{l}$ ) are essentially the same. Perhaps either the molecules of these compounds during GFC process is modified or individual fraction exerts antagonism effect in

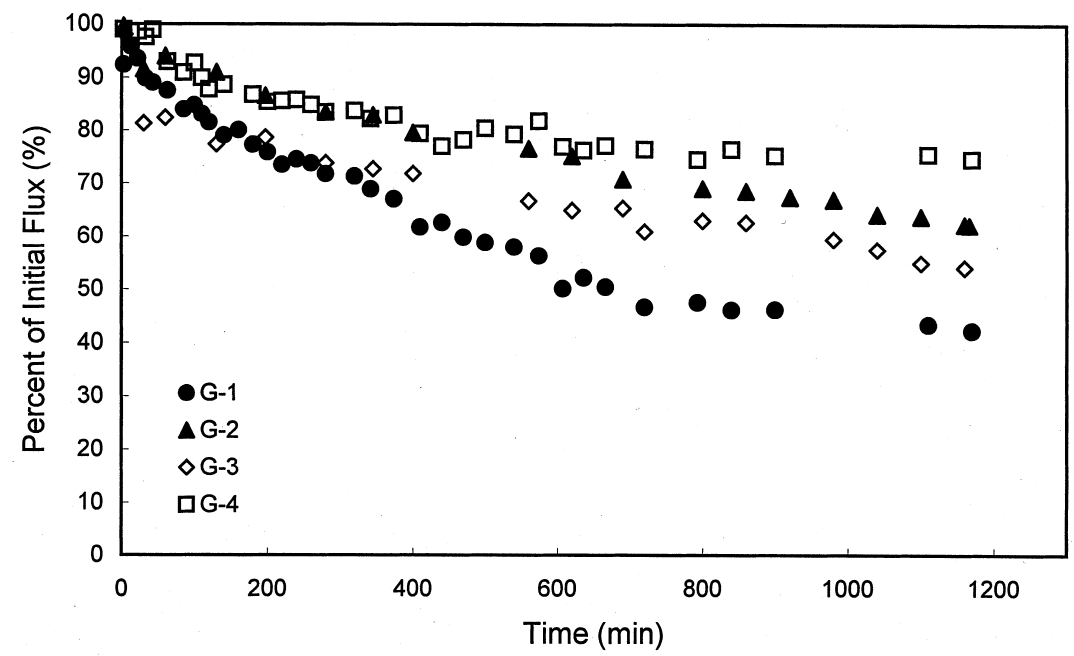

Fig. 4. Permeate flux of four fractionated humic substances operated at the constant feed concentration mode $(\mathrm{DOC}=5 \mathrm{mg} / \mathrm{l})$. 
the raw feed to account for the observed phenomenon. The intermolecular interactions among humic substance components and within a humic compound may change chemical and physical properties of humic substances (Leenbeer et al., 1988).

For the circulating system, the largest AMW fraction again exhibits the worst flux decline
(Fig. 5(a)). Unlike the previous case, the flux behavior of the unfractionated humic acid appears to be the composite of each fraction flux. As would be expected, the permeate quality is the best for G-1 fraction (Fig. 5(b)). As time progressed, permeate DOC concentration increased for G-3 and G-4 fractions; only small amount was rejected in the G-4
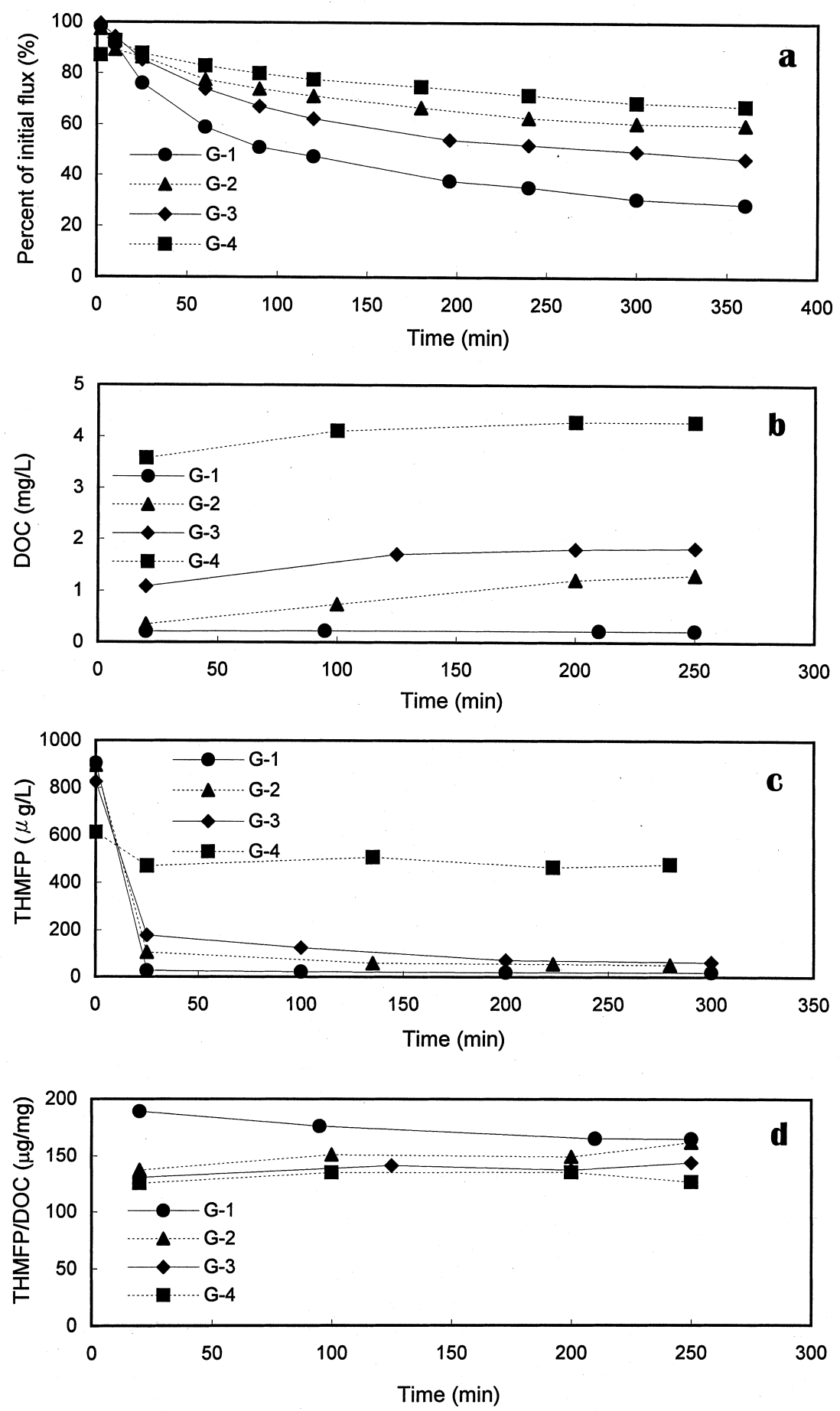

Fig. 5. Permeate quality and flux of four fractionated humic substances operated at the circulating mode (DOC $=5 \mathrm{mg} / \mathrm{l}$ ): (a) flux, (b) DOC, (c) THMFP and (d) THM yield. 


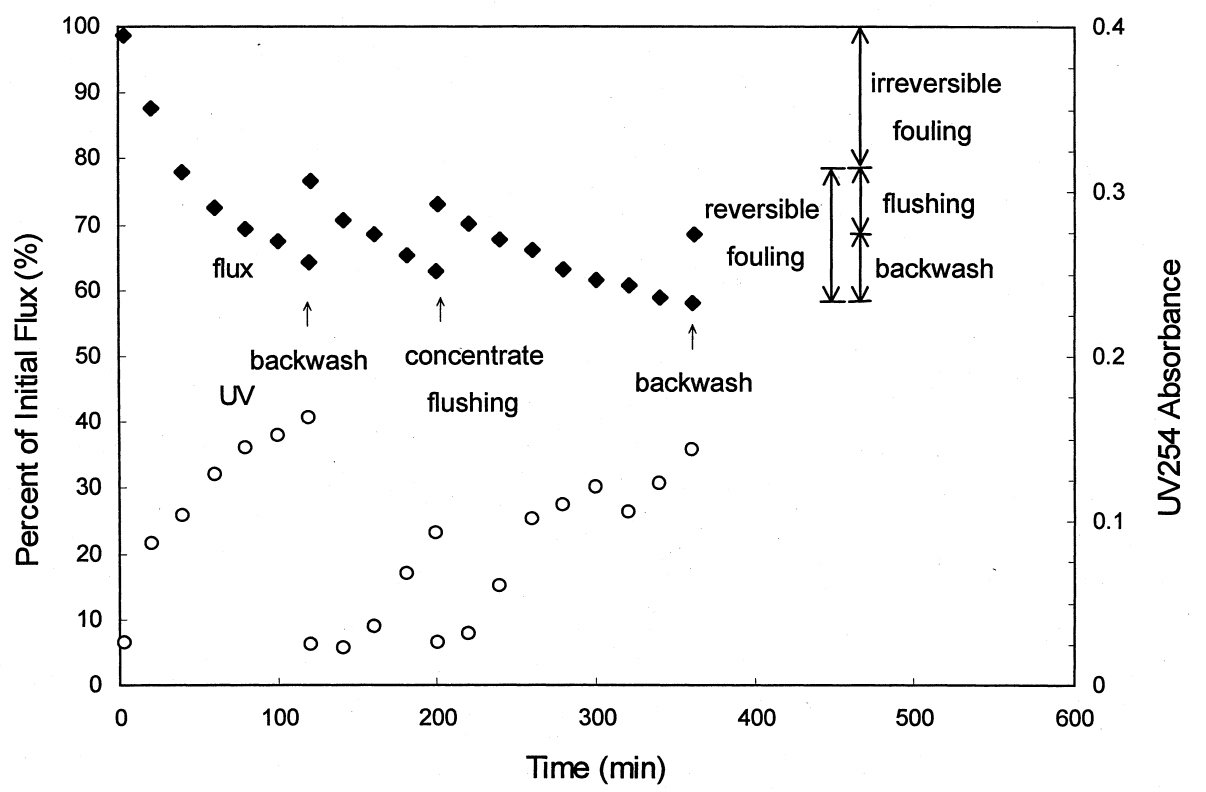

Fig. 6. Typical plots of flux recovery after backwash and loop flushing.

fraction at the end of experiment. The values of THMFP follow the DOC trend, i.e., almost 95\% THMFP exerted in the G-1 fraction could be removed, whereas only $10 \%$ removal for G-4 fraction after $4 \mathrm{~h}$ (Fig. 5(c)). Since DOC was also reduced accordingly, there still exists high THM yield in the UF treated water (Fig. 5(d)). This finding essentially reiterates the conclusion of other investigators (e.g., Laine et al., 1989, 1993) in that different UF systems with a relatively large MWCO are not effective for removal of DBP precursors. Nevertheless, the THM yield for G-1 permeate is highest (165-190 $\mu \mathrm{g} / \mathrm{mg} \mathrm{C}$ ), and G-4 the lowest (125-135) as shown in Fig. 5(d).

To further understand the extent of irreversible fouling, backwash of the membrane and loop flushing of the concentrate inside the module were performed in several experiments. A typical diagram for these treatments and the corresponding assumptions of membrane fouling phenomenon is shown in Fig. 6. Analogous to membrane fouling analysis (Wiesner and Chellam, 1992; Jones et al., 1993; Chang and Benjamin, 1996), it is assumed that by employing loop flushing, and hence wasting concentrate, any resulting flux improvement is due to removal of organics accumulated on the membrane surface, a phenomenon called membrane polarization (Pirbazari et al., 1992). Any additional flux recovery due to backwash with $\mathrm{NaOCl}$ is attributed to the removal of compounds that have been previously sorbed on the membrane surface. The difference between the sum of these two flux recoveries and the original flux at the end of experiment is assumed to be caused by the irreversible fouling, which cannot be removed by these two cleaning methods. The results (not shown) indicate that for the largest AMW fraction (G-1), the backwash or loop flushing does not improve permeate flux at all, hence the irreversible fouling accounts for almost all the flux decline. Specifically, adsorption of humic substances onto the hydrophobic membrane is responsible for the membrane fouling (Crozes et al., 1997). For the smallest AMW fraction (G-4), irreversible membrane fouling, however, is reduced to $72 \%$. As a result, the specific MW fraction of humic substances significantly affects the fouling mechanisms.

\section{PAC pretreatment}

The results of PAC pretreatment of humic acid (20 mg/1 DOC) after $24 \mathrm{~h}$ contact as a function of PAC dosage are shown in Table 3. At PAC $400 \mathrm{mg} / \mathrm{l}$, DOC removal efficiency is only slightly higher than $50 \%$. The filtrate (through $0.45 \mu \mathrm{m}$ paper) of each PAC-treated stream was then subject to GFC analysis. The chromatogram results (Fig. 7) clearly demonstrate that PAC is ineffective in removing AMW fraction of humic acid either $<300$

Table 3. Characteristics of PAC-treated water with the initial DOC $=20 \mathrm{mg} / 1$

\begin{tabular}{|c|c|c|c|c|}
\hline Group classification & PAC dosage $(\mathrm{mg} / \mathrm{l})$ & UV254 (Abs) & $\mathrm{DOC}(\mathrm{mg} / \mathrm{l})$ & DOC removal $(\%)$ \\
\hline P-1 & 80 & 1.558 & 18.6 & 7 \\
\hline $\mathrm{P}-2$ & 240 & 1.277 & 15.0 & 25 \\
\hline P-3 & 400 & 0.881 & 9.8 & 51 \\
\hline
\end{tabular}




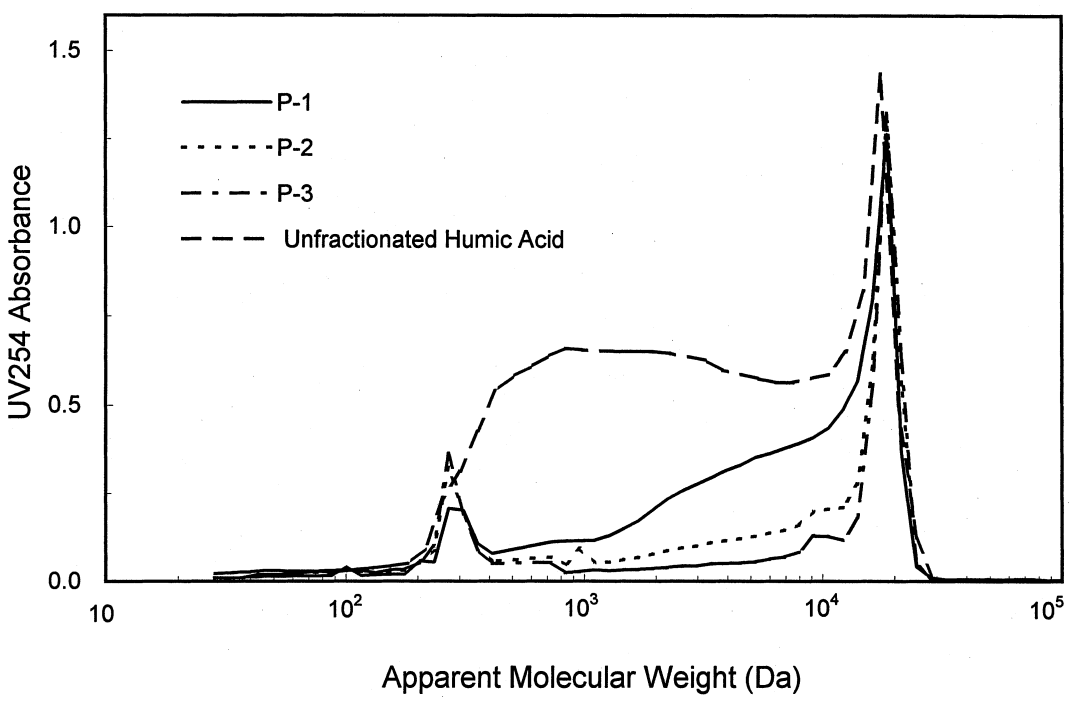

Fig. 7. GFC chromatograms for PAC-treated water.

or $>17,000$. The large molecules of humic substances are unable to penetrate the smaller pores of the PAC used. As for low MW molecules, they probably are of hydrophilic nature, and hence, are not amenable to PAC adsorption. The humic substances in the middle AMW range were removed by PAC; the higher the PAC dosage, the more DOC removed. Thus, membrane flux improvement, if any, must be due to removal of these compounds. On the other hand, PAC pretreatment may be more problematic in terms of flux decline, as discussed below.

The flux results of each PAC-treated stream in a constant concentration mode (5 mg DOC/1) are shown in Fig. 8. A similar flux behavior for these three classes indicates that membrane fouling is more likely due to molecules with AMW either less than 300 or greater than 17,000 . The extent of or- ganic removal in the middle AMW range by different PAC dosages appears not affecting permeate flux. Furthermore, the flux decline is much worse than that of unfractionated humic acid (Fig. 2(a)). This unexpected observation is definitely not due to operating conditions, since the initial flux remains essentially the same $\left(310-320 \mathrm{l} / \mathrm{m}^{2}-\mathrm{h}\right)$ as before. Previous membrane studies with PAC pretreatment of raw water have shown conflicting results, i.e., some improvement of permeate flux (Laine et al., 1990; Jacangelo et al., 1995), similar flux behavior (Crozes et al., 1993) and the worst flux decline with the feed in contact with PAC for a longer time in an NF system (Nilson and DiGiano, 1996). The adverse effect is apparently due to high affinity of nonadsorable humic substances for membrane surface. The smallest AMW molecules that remain after PAC pretreatment may be responsible for

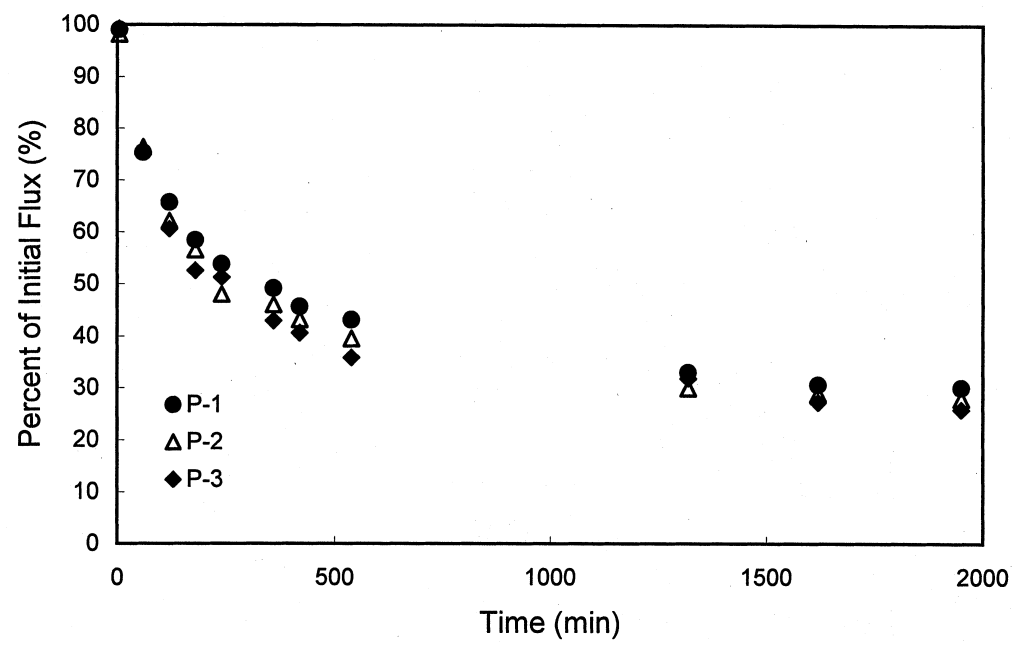

Fig. 8. Permeate flux of three PAC-treated waters operated at the constant feed concentration mode $(\mathrm{DOC}=5 \mathrm{mg} / \mathrm{l})$ 
membrane fouling as also reported by others (Crozes et al., 1993; Chang and Benjamin, 1996). Specifically, Crozes et al. (1993) emphasize the importance of adsorption of compounds onto membrane surface affecting membrane fouling. They reported that the adsorption of low MW tannic acid onto both hydrophobic and hydrophilic membranes caused significant flux decline.

A similar flux decline for these three classes of PAC treated solutions is also noted in the circulating mode at the initial DOC $=1.5 \mathrm{mg} / 1$ (Fig. 9(a)). However, as the feed concentration increases, the P1 solution (least PAC dosage) exhibits the lowest flux decline (Fig. 9(b)).

\section{UF-PAC system}

The purpose of this exercise is to observe any flux effect with the addition of PAC in the UF system, specifically the effect of different AMW fractions on the membrane performance. The results can substantiate the above PAC pretreatment finding. Prior to experiments, a batch study was conducted for the evaluation of the adsorption isotherm. The results after 24-h mixing at $130 \mathrm{rpm}$ and $25^{\circ} \mathrm{C}$ for the initial concentration of $5 \mathrm{mg} \mathrm{C} / 1$ at seven different PAC concentrations up to $100 \mathrm{mg} / \mathrm{l}$ appear to indicate that adsorption follows Freundlich isotherm. The concentration-time profile (not shown) further indicates that this particular $\mathrm{PAC}$ at $40 \mathrm{mg} / 1$ is not effective for the removal of $5 \mathrm{mg} \mathrm{C} / 1$ of humic acid; only $15 \%$ removal after $4 \mathrm{~h}$ and $20 \%$ after $24 \mathrm{~h}$. The same PAC was used for the previous PAC pretreatment study, thus the molecule residuals in this system are similar to those shown in Fig. 7.

The flux data (Fig. 10(a)) demonstrate that deionized water with PAC alone does not affect permeate flux at all; the permeate production is even better than that of deionized water alone. Jones et al. (1993) also reported that when $100 \mathrm{mg} / 1$ PAC was added to the deionized water and filtered through a hollow fiber UF system, there was no significant decreases in flux. They assumed that the PAC formed porous layer on the membrane surface to allow permeate pass through without affecting flux. Unfortunately, the combine UF-PAC system
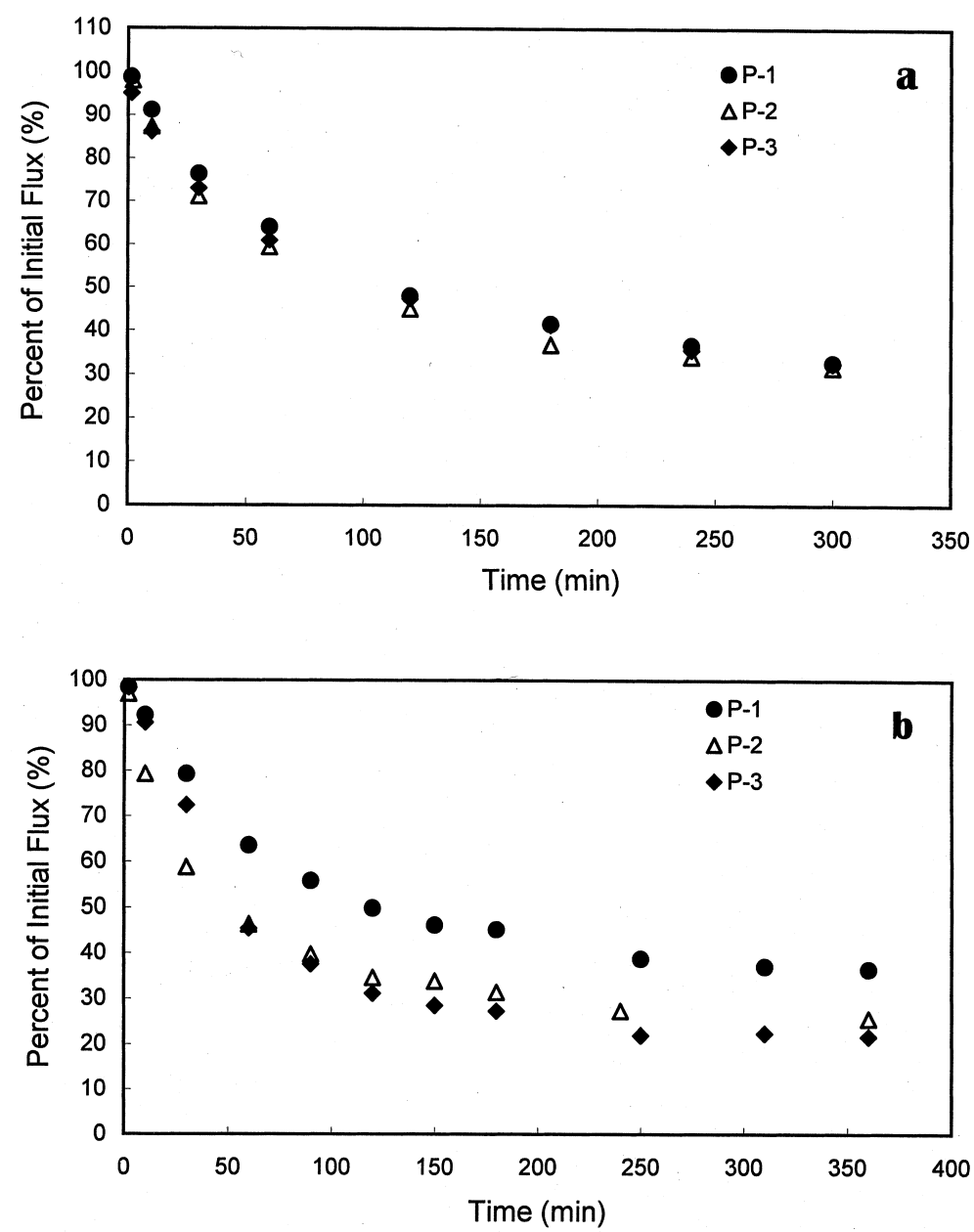

Fig. 9. Permeate flux of three PAC-treated waters operated at the circulating mode: (a) DOC $=1.5 \mathrm{mg} / \mathrm{l}$ and (b) DOC $=5 \mathrm{mg} / \mathrm{l}$. 
exhibits a significant flux decline. The adverse effect of PAC addition in terms of flux is in contrast to other studies (Adham et al., 1991; Jacangelo et al., 1995; Kim et al., 1996), although some have reported a similar phenomenon.

The possible fouling-causing substances are: (1) the remaining humic substances after contact with PAC as also demonstrated in previous PAC pretreatment study (Figs 9 and 10) and (2) PAC-organics mixture that formed on the membrane.
Qualitative information in supporting the latter explanation can be shown in SEM pictures (not shown). There is noticeable humic substances deposited on the surface of membrane, and a serious scale problem is present in the UF-PAC system. This dense layer somehow increase hydrodynamic resistance of the membrane (Newcombe et al., 1997) and, hence, affecting flux. This problem also affects permeate quality significantly (Fig. 10(b)). In fact, the DOC concentration increases after the in-
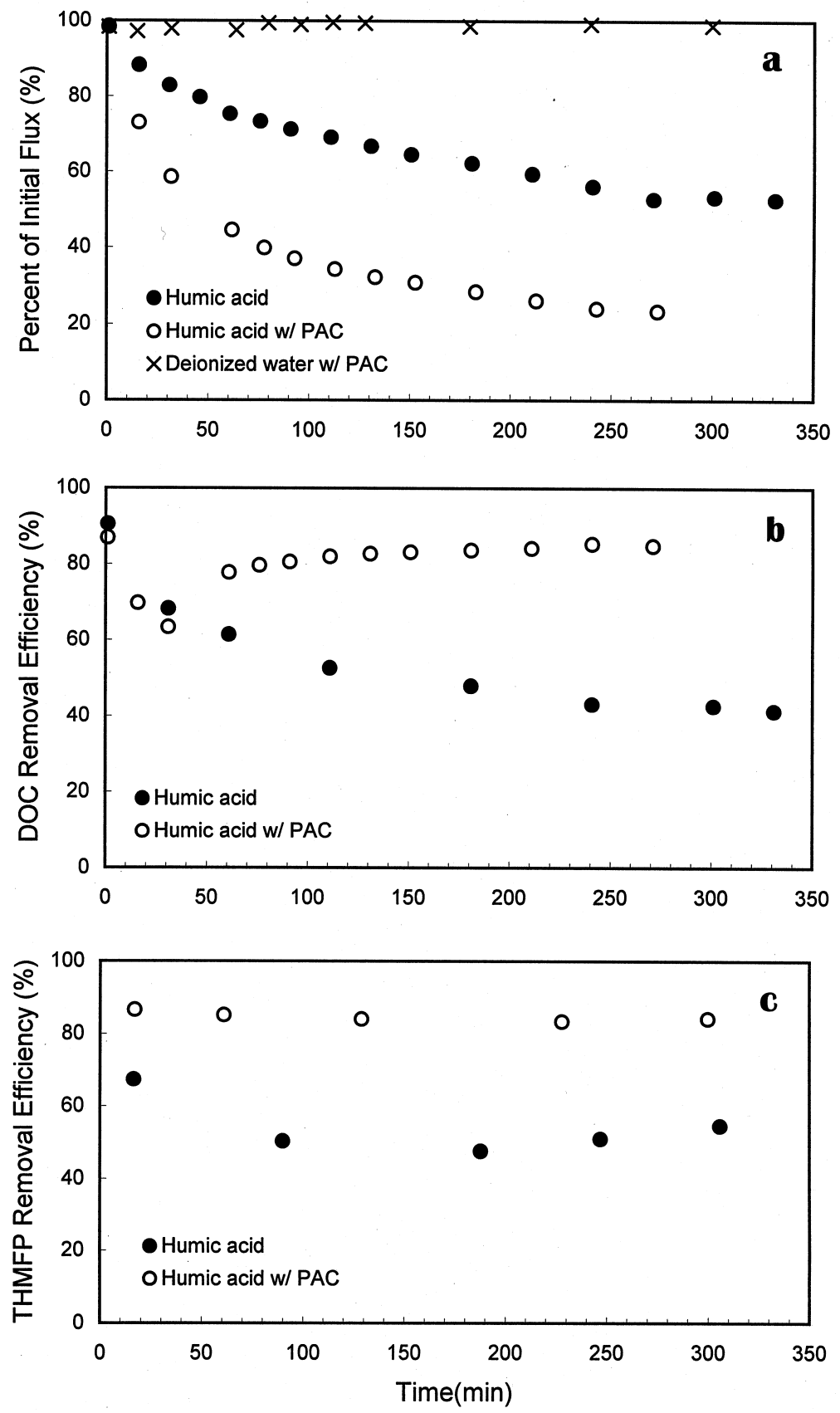

Fig. 10. Permeate quality and flux of the combined PAC-UF system operated at the circulating mode (DOC $=5 \mathrm{mg} / \mathrm{l}$ ): (a) flux, (b) DOC removal efficiency and (c) THMFP removal efficiency. 
itial drop. The corresponding THMFP with time (Fig. 10(c)) also indicates that the UF-PAC system hardly removes any THMFP.

To further observe the AMW effect, each GFC fractionated stream was filtered through the UFPAC system. The results (Fig. 11) indicate that G-4 fraction exhibits the least flux decline, and hence lowest DOC removal. However, the flux decline in all fractions is worse than those of UF systems without PAC (Fig. 2(b)). The results demonstrate that the use of this particular PAC either as a pretreatment agent or in conjunction in the integrated UF-PAC system may not be effective to alleviate membrane fouling.

\section{CONCLUSIONS}

UF, although its membrane having a relatively large molecular weight cutoff, is effective in reducing turbidity, particulates, organics and bacteria. However, the results of the present study clearly reaffirms the previous findings in that humic substances significantly facilitate permeate flux and UF system studied cannot effectively remove humic substances. Specifically, the humic substance fraction with the largest AMW (6.5-22.6 kDa) exhibits the worst flux decline with the best permeate quality, whereas the smallest AMW fraction (160-650 Da) exerts little effect on flux decline. Although, the UF system is able to remove a significant portion of THMFP in larger AMW fractions, the permeate THM yield in terms of $\mu \mathrm{g}$ THMs/mg DOC is still relatively high. Nevertheless, the use of UF in conjunction with chloramine practice may provide a better alternative to meet the stringent drinking water standards.

The use of PAC for pretreatment of humic substances or in combination with different UF operating systems to reduce membrane fouling actually yields a negative effect. The PAC used in the present study was ineffective in removing those AMW fractions less than 300 or greater than $17,000 \mathrm{Da}$;
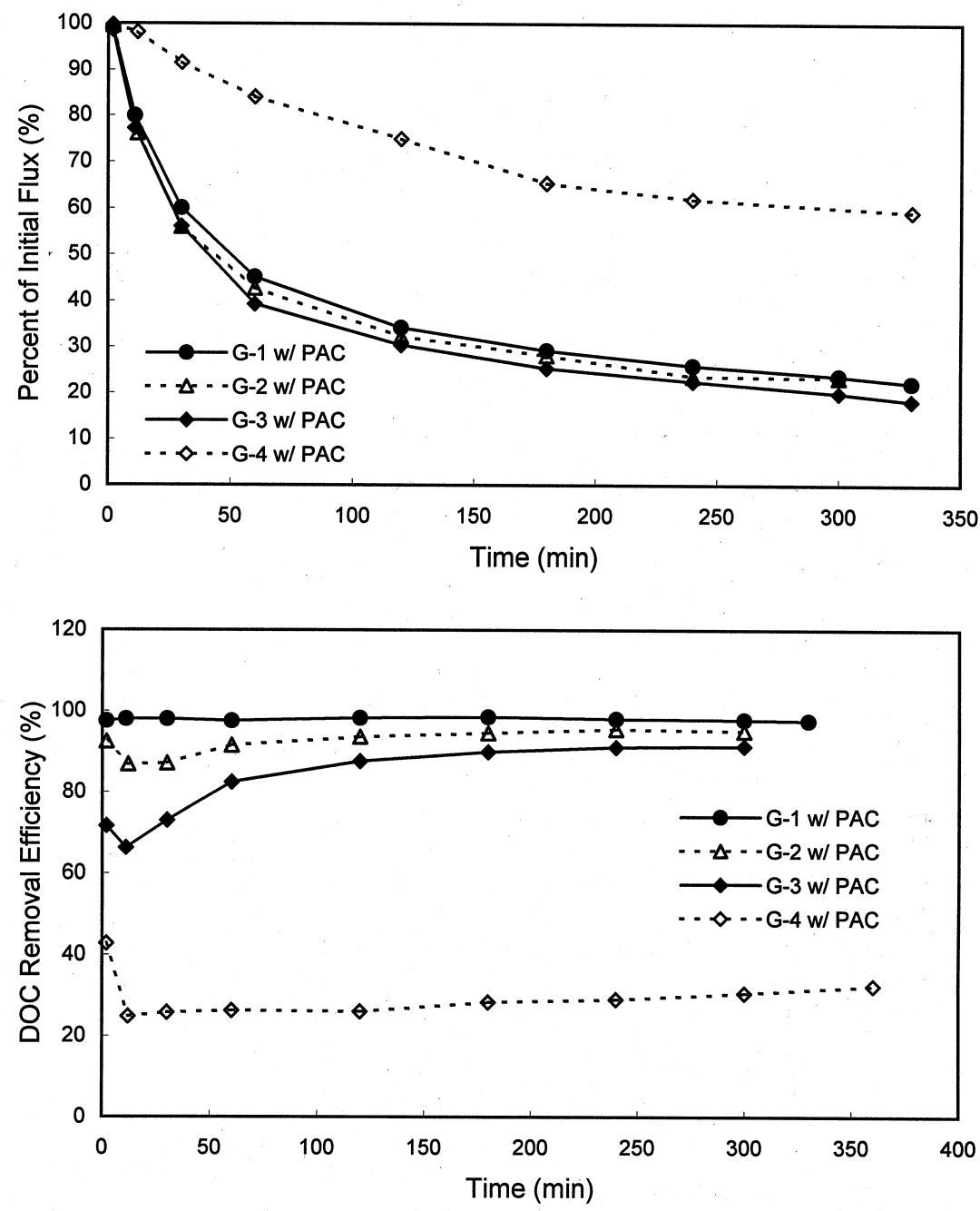

Fig. 11. Permeate quality and flux of four fractionated humic substances operated at the circulating mode $(\mathrm{DOC}=5 \mathrm{mg} / \mathrm{l})$ in the UF-PAC system. 
the higher the PAC dosage, the more removal in the middle range of thee AMW factions. The flux decline for PAC-treated streams is worse than the original humic substances with the same TOC concentration. Similarly, the combined UF-PAC system significantly decreases the flux.

Acknowledgements-This study was funded by the National Science Council (NSC) of the Republic of China in Taiwan under contract NSC 87-2211-E-002-007. OJH is grateful to the NSC for providing a visiting appointment (NSC 87-2811-E-002-0004) at the National Taiwan University during which time this paper was written.

\section{REFERENCES}

Adham S. S., Snoeyink V. L., Clark M. M. and Bersillon J.-L. (1991) Predicting and verifying organics removal by PAC in an UF system. J. Am. Water Works. Assoc. 83, 81-91.

Adham S. S., Snoeyink V. L., Clark M. M. and Anselme C. (1993) Predicting and verifying TOC removal by PAC in pilot-scale UF systems. J. Am. Water Works Assoc. 85, 58-68.

Adham S. S., Jacangelo J. G. and Laine J.-M. (1995) Low-pressure membranes: assessing integrity. J. Am. Water Works. Assoc. 87, 62-75.

Adham S. S., Jacangelo J. G. and Laine J.-M. (1996) Characteristics and costs of MF and UF plants. J. Am. Water Works. Assoc. 88, 22-31.

Agbekodo M. K., Legube B. and Cote P. (1996) Organics in NF permeate. J. Am. Water Works. Assoc. 88, 67-74.

Alarcon-Herrera M. T., Bewtra J. K. and Biswas N. (1994) Seasonal variations in humic substances and their reduction through water treatment processes. Can. J. Civ. Eng. 21, 173-179.

Amy G. L., Collins M. R., Kuo C. J. and King P. H. (1987) Comparing gel permeation chromatography and ultrafiltration for the molecular weight characterization of aquatic organic matter. J. Am. Water Works. Assoc. 79, 43-49.

Amy G. L., Sierka R. A., Bedessem J., Price D. and Tan L. (1992) Molecular size distributions of dissolved organic matter. J. Am. Water Works. Assoc. 84, 67-75.

APHA (1987) Standard Methods for the Examination of Water and Wastewater, 17th edn. Am. Public. Health Assoc., Washington, DC.

Chang Y. and Benjamin M. M. (1996) Iron oxide adsorption and UF to remove NOM and control fouling. $J$. Am. Water Works. Assoc. 88, 74-88.

Chellam S., Jacangelo J. G., Bonacquisti T. P. and Schaueer B. A. (1997) Effect of pretreatment on surface water nanofiltration. J. Am. Water Works. Assoc. 89, 77-89.

Collins M. R., Amy G. L. and Steelink C. (1986) Molecular weight distribution, carboxylic acidity, and humic substances content of aquatic organic matter: implications for removal during water treatment. Environ. Sci. Technol. 20, 1024-1032.

Crozes G. F., Anselme C. and Mallevialle J. (1993) Effect of adsorption of organic matter on fouling of ultrafiltration membranes. J. Membrane Sci. 84, 61-77.

Crozes G. F., Jacangelo J. G., Anselme C. and Laine J. M. (1997) Impact of ultrafiltration operating conditions on membrane irreversible fouling. J. Membrane Sci. 124, 63-76.
Fu P., Ruiz H., Thompson K. and Spangenberg C. (1994) Selecting membranes for removing NOM and DBP precursors. J. Am. Water Works. Assoc. 86(12), 55-72.

Hejzlar J., Szpakowska B. and Wershaw R. L. (1994) Comparison of humic substances isolated from peatbog water by sorption on DEAE-cellulose and Amberlite XAD-2. Water Res. 28, 1961-1970.

Hozalski R. M., Goel S. and Bouweer E. J. (1995) TOC removal in biological filters. J. Am. Water Works. Assoc. 87, 40-54.

Jacangelo J. G., Aieta E. M., Carns K. E., Cummings E. W. and Mallevialle J. (1989) Assessing hollow-fiber UF for particulate removal. J. Am. Water Works. Assoc. 81, 68-75.

Jacangelo J. G., Laine J.-M., Cummings E. W. and Adham S. S. (1995) UF with pretreatment for removing DBP precursors. J. Am. Water Works. Assoc. 87, 100112.

Jones K. L., Odderstol E. S., Wetterau G. E. and Clark M. M. (1993) Using a hydraulic model to predict hollow-fiber UF performance. J. Am. Water Works. Assoc. 85, 87-97.

Kim P. H.-S. and Symons J. M. (1991) Using anion exchange resins to remove THM precursors. $J$. Am. Water Works. Assoc. 83, 61-68.

Kim J.-S., Lee S.-J., Yoon S.-H. and Lee C.-H. (1996) Competitive adsorption of trace organics on membrane and powdered activated carbon in powdered activated carbon-ultrafiltration system. Water Sci. Technol. 34, 223-229.

Krasner S. W., Croue J. P., Buffle J. and Perdue E. M. (1996) Three approaches for characterizing NOM. $J$. Am. Water Works. Assoc. 88, 66-79.

Lahoussine-Turcaud V., Wiesner M. R. and Bottero J.-Y. (1990) Fouling in tangential-flow ultrafiltration: effect of colloid size and coagulation pretreatment. J. Membrane Sci. 52, 173-190.

Laine J.-M., Hagstrom J. P., Clark M. M. and Mallevialle J. (1989) Effects of UF membrane composition. J. Am. Water Works. Assoc. 81, 61-67.

Laine J.-M., Clark M. M. and Mallevialle J. (1990) Ultrafiltration of lake water: effect of pretreatment on the partitioning of organics, THMFP, and flux. $J . A m$. Water Works. Assoc. 82, 82.

Laine J.-M., Jacangelo J. G., Cummings E. W., Carns K. E. and Mallevialle J. (1993) Influence of bromide on low-pressure membrane filtration for controlling DBPs in surface waters. J. Am. Water Works. Assoc. 85, 8799.

Lee Y. and Clark M. M. (1997) A numerical model of steady-state permeate flux during cross-flow ultrafiltration. Desalination 109, 241-251.

Leenbeer J. A., Brown P. A. and Noyes T. I. (1988) Implications of mixture characteristics on humic-substance chemistry. In Aquatic Humic Substances: Influence on Fate and Treatment of Pollutants, eds. I. H. Suffet and P. MacCarthy. American Chemical Society, Washington, DC

Nakatsuka S., Nakate I. and Miyano T. (1996) Drinking water treatment by using ultrafiltration hollow fibre membrane. Desalination 106, 55-61.

Newcombe G., Drikas M. and Hayes R. (1997) Influence of characterised natural organic material on activated carbon adsorption: II. Effect on pore volume distribution and adsorption of 2-methylisoborneol. Water Res. 31, 1065-1073.

Nilson J. A. and DiGiano F. A. (1996) Influence of NOM composition on nanofiltration. J. Am. Water Works. Assoc. 88, 53-66.

Norton M. V., DiGiano F. A. and Hallen R. T. (1997) Selective separation of europium using polymerenhanced ultrafiltration. Water Environ. Res. 69, 244 253. 
Pirbazari M., Badriyha B. N. and Ravindran V. (1992) MF-PAC for treating waters contaminated with natura and synthetic organics. J. Am. Water Works. Assoc. 84, 95-103.

Pontius F. W. (1995) An update of the federal drinking water regs. J. Am. Water Works. Assoc. 87, 48-58.

Pontius F. W. (1997) Implementing the 1996 SDWA amendments. J. Am. Water Works. Assoc. 89, 18-36.
Wiesner M. R. and Chellam S. (1992) Mass transport considerations for pressure-driven membrane processes. $J$. Am. Water Works. Assoc. 84, 88-95.

Wiesner M. R., Hackney J., Sethi S., Jacangelo J. G. and Laine J.-M. (1994) Cost estimates for membrane filtration and conventional treatment. J. Am. Water Works. Assoc. 86, 33-41. 